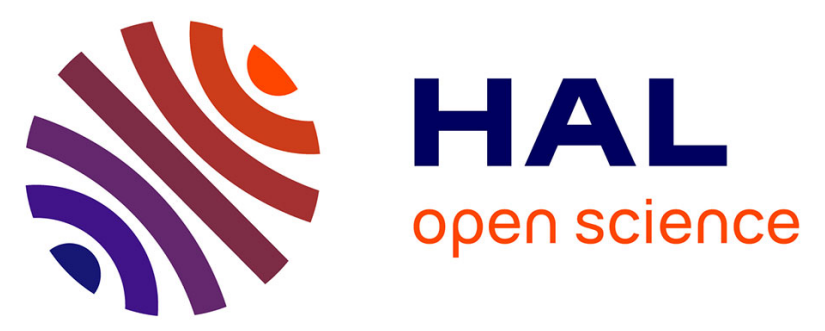

\title{
Extreme solar-terrestrial events of October 2003: High-latitude and Cluster observations of the large geomagnetic disturbances on 30 October
}

L. Rosenqvist, H. Opgenoorth, S. Buchert, I. Mccrea, O. Amm, Chantal Lathuillere

\section{To cite this version:}

L. Rosenqvist, H. Opgenoorth, S. Buchert, I. Mccrea, O. Amm, et al.. Extreme solar-terrestrial events of October 2003: High-latitude and Cluster observations of the large geomagnetic disturbances on 30 October. Journal of Geophysical Research Space Physics, 2005, 110 (A9), pp.A09S23. 10.1029/2004JA010927 . insu-00356504

\section{HAL Id: insu-00356504 https://hal-insu.archives-ouvertes.fr/insu-00356504}

Submitted on 19 Feb 2021

HAL is a multi-disciplinary open access archive for the deposit and dissemination of scientific research documents, whether they are published or not. The documents may come from teaching and research institutions in France or abroad, or from public or private research centers.
L'archive ouverte pluridisciplinaire HAL, est destinée au dépôt et à la diffusion de documents scientifiques de niveau recherche, publiés ou non, émanant des établissements d'enseignement et de recherche français ou étrangers, des laboratoires publics ou privés. 


\title{
Extreme solar-terrestrial events of October 2003: High-latitude and Cluster observations of the large geomagnetic disturbances on 30 October
}

\author{
L. Rosenqvist, ${ }^{1}$ H. Opgenoorth, ${ }^{2}$ S. Buchert, ${ }^{1}$ I. McCrea, ${ }^{3}$ O. Amm, ${ }^{4}$ and C. Lathuillere ${ }^{5}$ \\ Received 29 November 2004; revised 9 May 2005; accepted 14 June 2005; published 17 September 2005.
}

[1] The extremely large solar eruption on 28 October 2003 caused an intense geomagnetic storm at Earth. A second solar eruption on 29 October resulted in a reintensification of the storm about a day later. Similarities and differences between these two events in terms of solar eruption, solar wind driver, and their resulting effect on the near-Earth environment are investigated and put into context of previous works on storm geoeffectivness. Within the second storm some of the strongest substorms in the history of magnetic recordings occurred in northern Scandinavia. The aim of this study is to investigate the cause and resulting effects of these extreme geomagnetic disturbances on the ionosphere and upper atmosphere, focusing on the northern Scandinavian sector where these disturbances reached extremely high values. During this time period, well after the initial arrival of the Interplanetary Coronal Mass Ejection (ICME), the Cluster spacecraft were located at the flank of the magnetospheric tail. The satellites were passed several times by an inward and consecutively outward moving magnetopause in close relation to the substorm intensifications in northern Scandinavia. We propose that the evolution of these magnetospheric substorm intensifications are influenced by the changing dynamics of the solar wind in the form of increased pressure occurring after a prolonged period of southward Interplanetary Magnetic Field (IMF) and thus excessive energy loading into the magnetosphere prior to the onset of the intensifications. We present evidence of external pressure pulse triggering and possibly also quenching of these substorm onsets and recoveries. In addition, EISCAT data have been used to investigate the detailed local behavior of the ionospheric plasma, giving rise to such extreme disturbances. We found that in this case, extreme combinations of enhanced conductivity and intense electric field resulted in very high current intensities (westward electrojet $\sim 7.4 \mathrm{MA}$ ) and very fast onset of such currents. The $\frac{\mathrm{d} B}{\mathrm{~d} t}$ associated geomagnetically induced currents caused power failures in southern Sweden.

Citation: Rosenqvist, L., H. Opgenoorth, S. Buchert, I. McCrea, O. Amm, and C. Lathuillere (2005), Extreme solar-terrestrial events of October 2003: High-latitude and Cluster observations of the large geomagnetic disturbances on 30 October, J. Geophys. Res., 110, A09S23, doi:10.1029/2004JA010927.

\section{Introduction}

[2] Nonrecurrent geomagnetic storms are the terrestrial manifestation of large eruptions of plasma from our Sun out into interplanetary space. A geomagnetic storm displays global effects such as ring current intensification which typically continues for several days or more; however, local energetic effects, such as the violent deposition of significant amounts of energy and momentum into the upper

\footnotetext{
${ }^{1}$ Swedish Institute of Space Physics, Uppsala, Sweden.

${ }^{2}$ Research and Scientific Support Department, European Space Agency/ European Space Research and Technology Centre, Noordwijk, Netherlands. ${ }^{3}$ Rutherford Appleton Laboratory, Chilton, Didcot, UK.

${ }^{4}$ Finnish Meteorological Institute, Helsinki, Finland.

${ }^{5}$ Laboratoire de Planétologie de Grenoble, Grenoble, France.

atmosphere, the injection of energetic particles into nearEarth space, the sudden onset of huge current system in the high-latitude and subauroral ionosphere, and consequent electromagnetic induction effects in conductors at the ground, occur within a few tens of minutes, usually during several individual episodes. These more local violent events resemble in most of its features major substorms. The most violent substorm within the geomagnetic storm on 29-31 October, which we report and study in this paper, occurred around 2000 UT on 30 October and seems to have driven inductive currents which resulted in the loss of electricity for about 50,000 people in southern Sweden. Within a short time a huge amount of energy has been dissipated in the upper thermosphere, as will be shown. An obvious question, from a practical viewpoint, is whether this event could have been predicted, as it occurred well after the sudden storm commencement. At the same time this question challenges our basic understanding of what 
the causes of large geomagnetic disturbances are and how the energy is transported in the solar wind-magnetosphereupper atmosphere system. After reviewing previous work on the identification of various triggers for substorms and substorm-like activities, we will present an overview of the events that lead to the gigantic substorm on 30 October and investigate in detail what has caused this event and whether similar events will be likely to occur again under comparable circumstances.

[3] An important criterion for the occurrence of geomagnetic storms is a sufficiently strong and prolonged period of southward orientated Interplanetary Magnetic Field (IMF), resulting in strong dawn-to-dusk electric fields at Earth. One of the many interplanetary sources of such regions of negative $B_{z}$ fields are so-called magnetic clouds [e.g., Klein and Burlaga, 1982; Burlaga et al., 1987] which are formed by the magnetic field, that is embedded in solar plasma ejected during so-called Coronal Mass Ejections (CMEs). Magnetic clouds are characterized by enhanced magnetic field strengths and a smooth rotation of the magnetic field vector over a 1-day period following a turbulent sheath region. Detailed models have shown that what appears to be a "cloud" at one observing satellite is, indeed, a flux rope emerging from the Sun [Burlaga et al., 1981]. The $B_{z}$ component within the observed portion of such a flux rope can therefore be either north-south (NS) or south-north (SN) orientated. Zhang and Burlaga [1988] found that the storm onset is correlated with the magnetic field direction of the cloud, normally beginning when the cloud $B_{z}$ turns south. They also found that the strongest storms, characterized by the Dst index, occurred for SN storms. However, they did not attribute this to the polarity of the cloud but concluded that it might be due to (on average) higher bulk flow speed which they observed in SN clouds. Generally, the Earthdirected solar wind speed and the southward component of the IMF are of most importance in terms of storm geoeffectivness [Snyder et al., 1963; Fairfield and Cahill, 1966] in comparison the duration of the region of southward IMF has been suggested to be less important [Wang et al., 2003]. The geoeffectivness of the different regions of magnetic clouds, sheaths, leading and trailing fields have been investigated by Zhang et al. [2004]. It was found that the sheath and leading regions are equally effective at causing magnetic storms. Although, magnetic clouds that are fast enough to drive shocks have been found to be more geoeffective because of the combined effect of their high ejecta fields and due to draping/shock effects [Gonzalez et al., 1999].

[4] During storm development, intense magnetospheric substorms frequently occur. Baumjohann et al. [1996] suggested that substorms occurring during the main phase of magnetic storm activity could be significantly different from those occurring during nonstorm times (Dst $>-25 \mathrm{nT}$ ). In contrast, a more recent study found that there are no qualitative differences between the two classes of substorms and thus no reason to believe that different mechanisms drive substorms during storm and quiet times [McPherron and $\mathrm{Hsu}, 2002]$.

[5] Another outstanding question in magnetospheric physics is related to the triggering mechanism of the substorm expansion phase. Typically, a magnetospheric substorm can be described as an energy storage-release process. The energy is first stored in the magnetospheric tail during the substorm growth phase then released by a large-scale instability and dissipated in the magnetosphereionosphere system. The initiation of the substorm onset instability can be described by two alternative models, the Near-Earth Neutral Line (NENL) model which asserts that reconnection in the midmagnetotail initiated by an internal tail instability is the primary process [Baker et al., 1996] or a Current-Disruption (CD) model which proposes that a current sheet instability in the inner magnetotail leads to a cross-tail current disruption [Lui, 1996]. Both of these processes suggest a spontaneous release of stored energy due to an internally driven instability in the magnetosphere. Another possible onset trigger mechanism has been related to changes in the interplanetary medium, either variations in the interplanetary magnetic field or by changes in the solar wind. Several studies have shown that northward turnings of the IMF can be considered as possible triggers [e.g., Rostoker, 1983; Lyons et al., 1997]. In addition, a reduction of the magnitude in IMF $\mathrm{B}_{y}$ has been suggested as another possible trigger candidate [Troshichev et al., 1986]. Several studies have also shown that Sudden Storm Commencements (SSCs) or Sudden Impulses (SI) produced by solar wind shocks may lead to the expansion phase onset of a substorm [e.g., Schieldge and Siscoe, 1970; Burch, 1972]. However, a recent statistical study by Liou et al. [2003] suggests that interplanetary shocks can produce negative magnetic bays but not auroral breakups and thus shock compression is not likely to trigger substorms but rather enhance magnetospheric currents and the overall auroral particle precipitation. Another detailed statistical study by $H s u$ and McPherron [2003] shows that $60 \%$ of all substorms appear to be externally triggered. Of these the majority of the events were triggered by changes in $B_{z}$, while $10 \%$ appear to be triggered by a reduction in $B_{y}$ and about $7 \%$ by dynamic pressure changes. The remaining $40 \%$ could not be accounted for by any external trigger.

[6] The question of whether substorms are always externally triggered remains a controversial question in the scientific community. However, little has been done to separate between nonstorm and storm time substorms in terms of the effectivity of such various trigger mechanisms and at the same time taking into account different preconditioned magnetospheric states. This may be important, as it can be expected that the magnetosphere reacts differently to one and the same external trigger mechanism during storm times than during quiet conditions due to the excessive energy loading into the magnetosphere prior to the substorm onset. In this study we present a case study of several substorm-like intensifications within the main $B_{z}$ negative phase of a geomagnetic storm. We will present evidence that these intensifications are triggered by moderate new compressions of the magnetosphere well after the initial interplanetary shock compression. We also attempt to locally quantify the energy dissipation into the ionosphere system and review some related effects which these disturbances had on Earth.

\section{Instruments}

[7] This paper aims to give initially a global view of the entire storm event of interest to lay a foundation for a more 


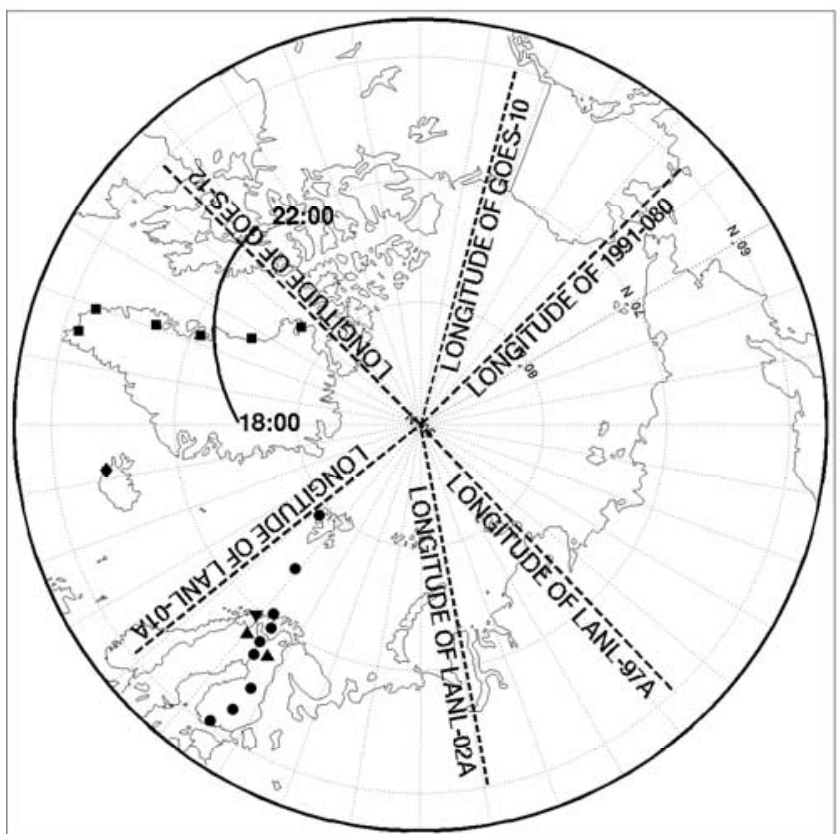

Figure 1. Polar plot at 2000 UT for 2003/10/30, looking down on the northern hemisphere with local noon at the top of the page. The IMAGE magnetometers employed in the study are pointed out by circles, while the Greenland chain is marked by black squares and the Iceland station by a black diamond. The location of several geosynchronous satellites are marked by dashed lines. The EISCAT Tromsø (north-west), Kiruna (south-west), and Sodankylä (southeast) facilities are marked by triangles. Also, the Cluster footprints on the ground is shown for the time period of 1800-2200 UT, using the Tsyganenko89 magnetic field model.

detailed description of a specific event around 2000 UT on 30 October 2003, when major geomagnetic disturbances occur above Scandinavia. Hence a vast set of instruments have been used in this study. The characteristics of the solar driver were evaluated in the solar wind at the L1 point with the magnetic field (MAG/H0) and Solar Wind Electron, Proton, and Alpha Monitor (SWEPAM) instruments on board ACE. However, both the density and velocity of the solar wind was so strong that the ACE/SWEPAM instrument was completely saturated and thus only search mode data ( $\sim 33$ min time resolution) are available from 1241 UT on 28 October through 0051 UT on 31 October. Reliable data of the solar wind speed during this period have been restored from one-dimensional Maxwellian fits to the measured data. However, the calculated proton densities were in disagreement with densities obtained from the Geotail Plasma Wave Instrument (PWI) from 0600 UT on 29 October to 0400 UT on 30 October and have been replaced with fill values. Density measurements between PWI and SWEPAM were in good agreement prior to 0600 UT on 29 October and after 1100 UT on 31 October. No independent density measurements are available between 0400 UT on 30 October and 1100 UT on 31 October since Geotail was in the magnetosphere during this period. Consequently uncertainties could be large in this time interval (see Skoug et al. [2004] for more details).
[8] The Los Alamos National Laboratory (LANL) satellite database can provide both information about the spatial structure of the magnetopause and about substorm related particle injections at geosynchronous orbit. The instrument used throughout this study is the Synchronous Orbit Particle Analyser (SOPA) instrument [Reeves et al., 1996] which measures electron energy fluxes in the energy range $50 \mathrm{keV}$ to about $26 \mathrm{MeV}$. In addition two other geostationary spacecraft, GOES-12 and GOES-10, have been employed to identify geosynchronous orbit magnetopause crossings and to evaluate the magnetospheric energetic particle environment using the magnetic field data and energetic particle data, respectively, from the Space Environment Monitor (SEM) mission. The longitudes of the geostationary satellites are shown in Figure 1. The map in Figure 1 is rotated such that local midnight is at the bottom center of the map at 2000 UT.

[9] Magnetic field measurements from several groundbased observatories have been studied in this paper. The location of the Scandinavian IMAGE magnetometer network [Viljanen and Häkkinen, 1997], the Greenland magnetometer chain operated by the Danish Meterorological Institute (DMI) [Friis-Christensen et al., 1985], and the Leirvogur magnetometer station on Iceland are marked in Figure 1 with black circles, black squares, and a black diamond, respectively. The symmetric disturbance field in $\mathrm{H}$, the SYM-H index from the World Data Center (WDC) in Kyoto, which is essentially high-resolution (1 min) Dst data, has been used to estimate the overall strength of the storms and for identifying increases in dynamic pressure in the solar wind. The European Incoherent Scatter (EISCAT) radar [Folkestad et al., 1983] measures disturbances in the magnetosphere and the ionized parts of the atmosphere. One EISCAT transmitter site is located in Troms, Norway, with additional receiver stations in Sodankylä, Finland, and Kiruna, Sweden (marked by triangles in Figure 1).

[10] The Cluster satellites [Escoubet et al., 2001] are located at the duskside flank of the magnetosphere during the time period of interest (around 2000 UT on 30 October) and the projected footprints, assuming a model of the geomagnetic field according to the Tsyganenko89 model [Tsyganenko, 1989], between 1800 and 2200 UT are shown in the map. Figure 2 depicts the relative locations of the Cluster spacecraft in the $\mathrm{XZ}_{\mathrm{GSE}^{-}}$and $\mathrm{YZ}_{\mathrm{GSE}}$-planes at the time of 2004 UT. From the four Cluster spacecraft we will use data from the Fluxgate Magnetometer (FGM) measurements [Balogh et al., 2001] and the Cluster Ion Spectrometry (CIS) instrument [Réme et al., 2001].

\section{Overview of Event}

[11] An unexpected, though not untypical for the declining phase of the solar cycle, period of strong geomagnetic activity started on 24 October 2003 with the sudden appearance of several large sunspot groups, as the Sun rotated into view, on the previously very quiet solar disk. The dominant feature was Active Region 10486 that produced some of the most intense solar flare and CME activity on record. In the following we will focus on the 3-day period between 29 and 31 October 2003, when the effects of 


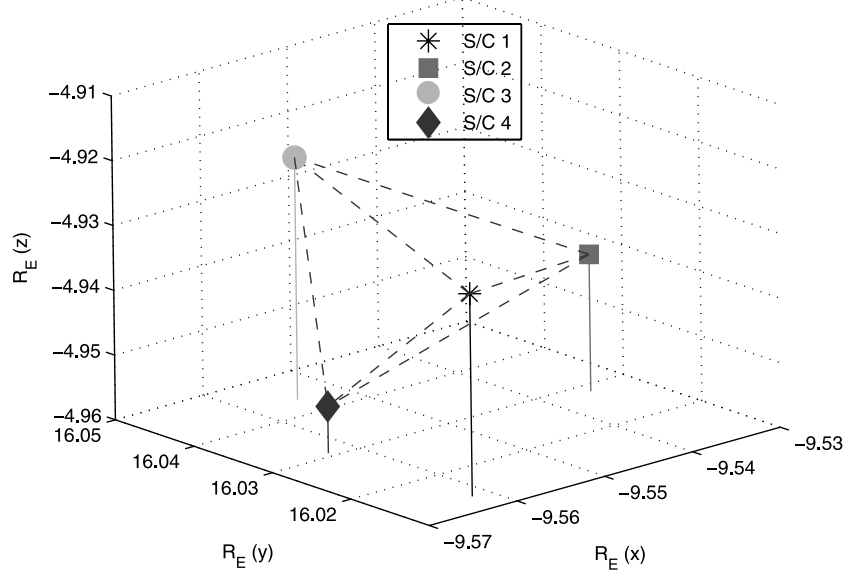

Figure 2. The Cluster s/c relative locations at 2004 UT on 30 October 2003. See color version of this figure at back of this issue.

this chain of solar activity caused major disturbances at Earth.

\subsection{Observations}

\subsubsection{Solar Eruptions}

[12] Two large solar eruptions from Active Region 10486 were favorably positioned on the solar disk for most of the associated ejecta to propagate earthward on their transit through the interplanetary medium. The first flare occurred on 28 October, 1110 UT and was classified as an X17 flare by the Space Environment Center (SEC) at the National Oceanic and Atmospheric Administration (NOAA) and the subsequent large flare on 29 October, 2050 UT was classified as X10. These two sudden eruptions of energy in the solar atmosphere were associated with two large CMEs observed by the SOHO spacecraft, resulting in solar wind shocks, flow discontinuities, and large interplanetary magnetic field disturbances.

\subsubsection{Solar Wind and Magnetospheric Response}

[13] The arrival of the first Interplanetary CME (ICME) was associated with a strong and clear SSC on 29 October at 0611 UT as detected by ground-based equatorial magnetometers. In comparison the second ICME, arriving at around 1630 UT on 30 October did not show any clear evidence of an associated SSC. The times of arrival are marked with vertical dashed lines in Figure 3, implying a transit time from Sun to Earth of less than 20 hours. The rapid arrival of these structures at Earth implies an extremely fast solar wind of more than $2000 \mathrm{~km} / \mathrm{s}$, in accordance with the restored data from the SWEPAM detector on board ACE (top panel in Figure 3). The magnetic field topology of the two ICMEs can be seen in magnetic field measurements from ACE in the second and third panel from the top in Figure 3. The magnetic field configuration behind both of the sheaths is characterized by a magnetic cloud structure described in the introduction section. A strong bipolar structure is seen within the shock region of the first ICME. The magnetic field strength changes from an average of $9 \mathrm{nT}$ of the interplanetary quiet field to a maximum of $60 \mathrm{nT}$ across the shock. This indicates an interplanetary shock with a Mach number of over 6 since the magnetic field jump across the shock is roughly proportional to the Mach number [Tsurutani and Gonzalez, 1987]. While the first larger magnetic cloud has a smooth northward to southward rotation of the $B_{z}$ component of the magnetic field inside the main ICME body, the second magnetic cloud has a reversed polarity. Furthermore, the structure of the second cloud is more complicated with an additional north-south oriented structure within the main region of the cloud. The sheath region of the first cloud is more magnetically intense than the second cloud, reaching the extremely low value of $B_{z}=$ $-59 \mathrm{nT}$. However, the second ICME reaches lower negative $B_{z}$ values in the main body of the magnetic cloud than the first one $\left(B_{z}=-34.8 \mathrm{nT}\right.$ versus $\left.B_{z}=-27.3 \mathrm{nT}\right)$, though the duration of the region of negative $B_{z}$ is about half as long as for the first cloud. The magnetospheric energetic particle environment as seen by the GOES-10 satellite (bottom panel in Figure 3) is dominated by the Solar Energetic Particle (SEP) event following the first flare. The arrival of the two ICMEs is in this data set associated with two large enhancements mainly in the lower energy range.

[14] In summary, even though the first ICME has a stronger shock, a stronger negative $B_{z}$ in the sheath region, and a larger amount of magnetic flux in the associated flux rope, the successive cloud appears in total to be more geoeffective than the first cloud considering the extremely low SYM-H index reached (fourth panel from the top in

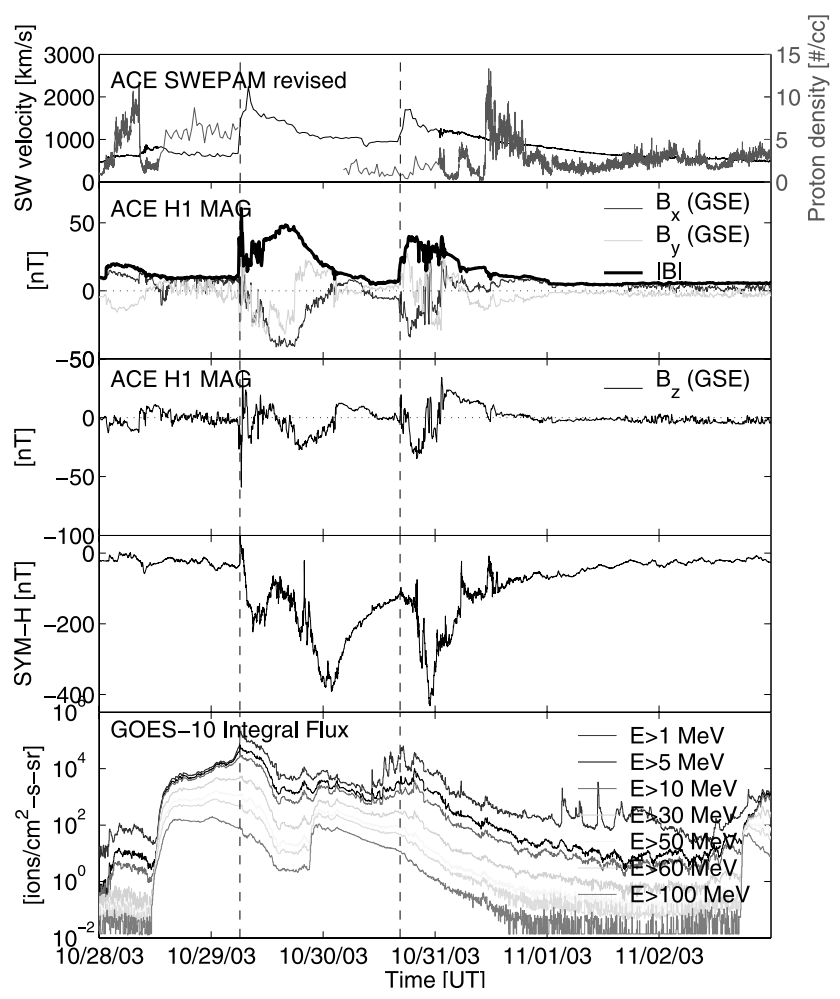

Figure 3. Summary of events of late October to the beginning of November 2003. From top to bottom is the revised ACE SWEPAM solar wind velocity and density (courtesy of T. Zurbuchen), the ACE H1 magnetic field data in GSE coordinates, the SYM-H index, and the integral proton flux from the GOES-10 spacecraft. The vertical dashed lines indicate the arrival of the two geomagnetic clouds at Earth. See color version of this figure at back of this issue. 


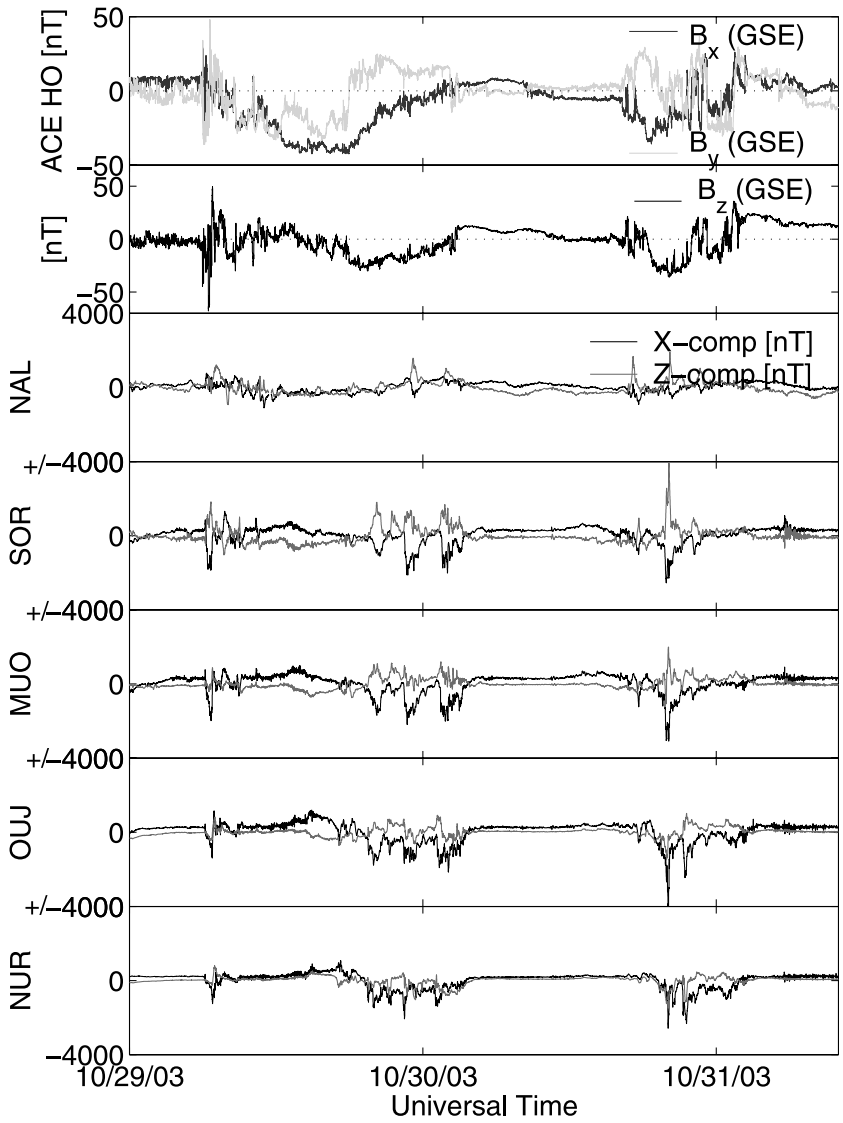

Figure 4. Unshifted solar wind data in GSE-coordinates from ACE H0 (time resolution $16 \mathrm{~s}$ ) and selected $\mathrm{Bx}$ and Bz-component magnetograms from the IMAGE network. See color version of this figure at back of this issue.

Figure 3). In addition, considering the coupling of the magnetic cloud to the magnetosphere, the second cloud creates much stronger substorms in the nightside sector, as seen in the IMAGE magnetometer data (Figure 4). The substorms on 30 October, centered around 20 UT, were amongst the strongest ever recorded in northern Scandinavia $(>4000 \mathrm{nT})$. The reason for the higher geoeffectiveness of the second cloud appears to be due to the lower value of the southward component of the IMF reached during the first phase $\left(B_{z}<0\right)$ of the cloud, which implies that the compressed negative $B_{z}$ in the leading fields of the magnetic cloud have the most prominent geoeffectivness regardless of other cloud characteristics (e.g., shock strength, sheath fields, duration, velocity). The difference in geoeffectivness may also be found in the reversed polarity of the two magnetic clouds ( $B_{z} \mathrm{NS}$ for the first cloud and $B_{z} \mathrm{SN}$ for the second cloud), as suggested by Zhang and Burlaga [1988]. However, the solar wind bulk flow speed is higher for the first cloud as recorded by the instruments on ACE which is in contradiction to their interpretation of a higher bulk flow speed as the cause of stronger magnetic storms observed for SN clouds.

\section{Major Substorm in Scandinavia}

[15] As reported in the previous section the second magnetic cloud associated with the X10 flare from Active
Region 10486 of the October 2003 event caused the most dramatic effects on the Earth's magnetosphere during this sequence of events. In the following we will focus on a time period around 2000 UT on 30 October, which is right inside the negative $B_{z}$ phase of the second ICME. During this time period the Cluster spacecraft are crossed by an inward and consecutively outward moving magnetopause simultaneously with the occurrence of major substorm-like intensifications in northern Scandinavia.

\subsection{Observations}

\subsubsection{Solar Wind and Magnetosphere}

[16] At 2007 UT on 30 October 2003, a major power system blackout occurred in the city of Malmö in southern Sweden resulting in the loss of electricity for 20-50 min for about 50,000 inhabitants. The power grid blackout was caused by geomagnetically induced currents and occurred simultaneously as extremely high substorm activity over Scandinavia, as illustrated in Figure 5. The dashed arrow indicates the time of the power loss in Malmö.

[17] Five major substorm-like intensifications are seen in the selected magnetograms from IMAGE in Figure 5 during the first phase $\left(B_{z}<0\right)$ of the second magnetic cloud (onsets marked with solid arrows in Figure 5). Also, data from the Leivogur magnetometer from Iceland, located further duskward of IMAGE, and from the Greenland magnetometer chain located on the dayside half of the ionosphere are shown in order to get a global view of the disturbed

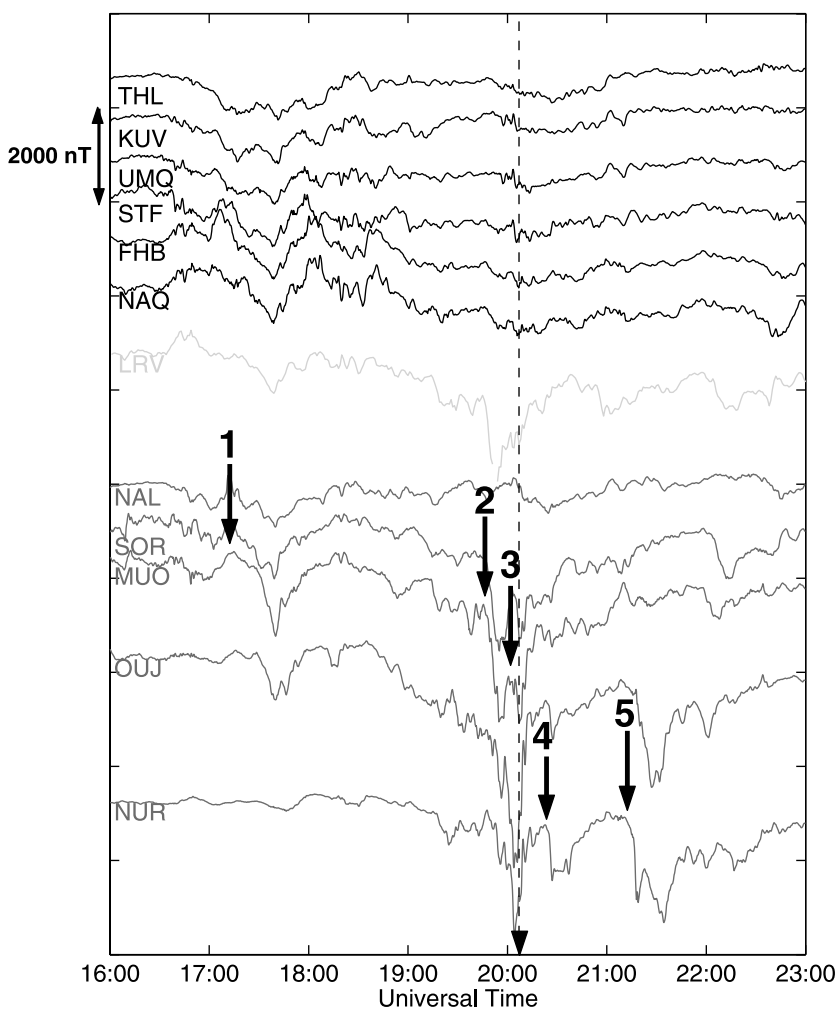

Figure 5. Ground magnetic H-component (Greenland) and X-components (IMAGE, LRV) for different local times. The vertical dashed arrow indicates the time of the power loss in Malmö in southern Scandinavia at 2007 UT. See color version of this figure at back of this issue. 


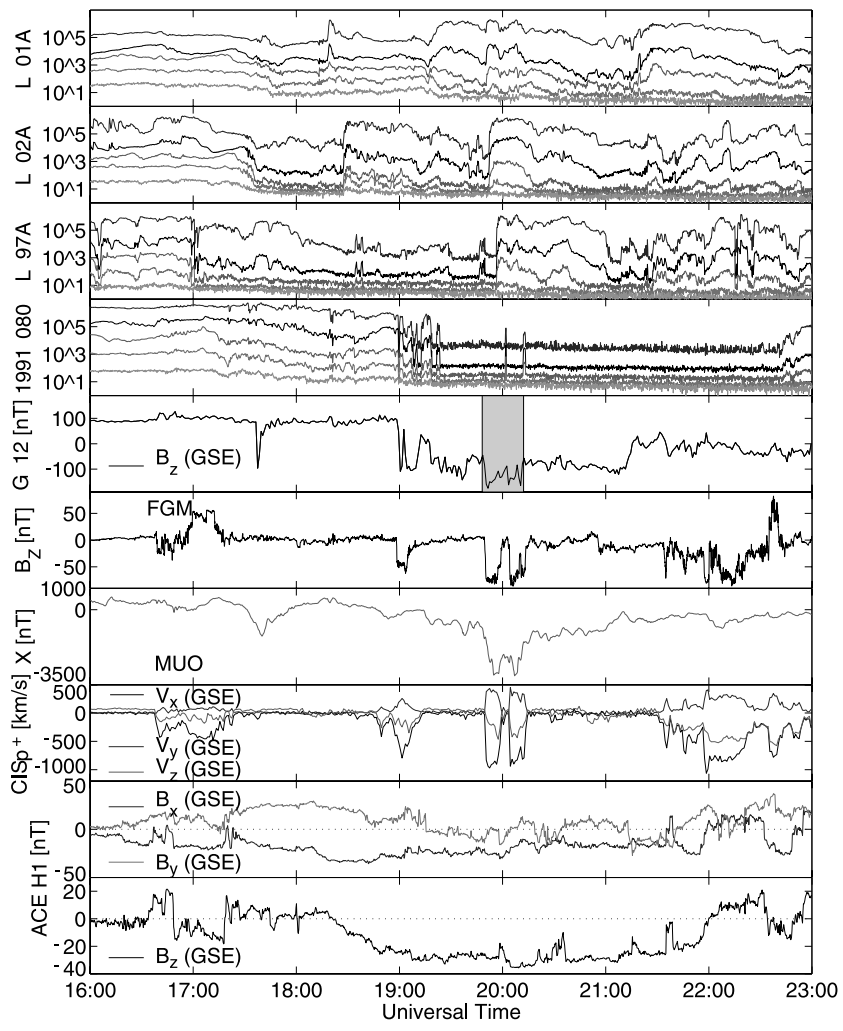

Figure 6. Summary of events on 30 October 2003. From top to bottom are shown low-energy electrons $(50-315 \mathrm{keV})$ from four LANL geosynchronous satellites, magnetic field measurements from GOES-12, magnetic field measurements from Cluster FGM, the X-component from the MUO magnetometer, proton bulk flow velocity from Cluster CIS, and unshifted magnetic field measurements from ACE in the solar wind. See color version of this figure at back of this issue.

conditions. Shortly after the arrival of the magnetic cloud at $1630 \mathrm{UT}$, almost all stations show reactions in the $B_{X}($ or $\mathrm{H})$ component in response to the southward turning of the IMF. The second substorm-like intensification starts at 1948 UT north of Muonio (MUO) which then develops further south with a maximum intensity at around the latitude of Oulujärvi (OUJ). Only about 15 min later (2003 UT) a third intensification starts almost simultaneously at a wide range of latitudes (including the latitude of MUO). A smaller intensification at extremely low, normally subauroral latitudes initiates at 2023 UT, leading to a fourth but less intense poleward expansion of the overall electrojet system (compare with Figure 8) and the last intensification starts at 2109 UT, again over southern Finland. The four latter intensifications are more local than the first one since no significant disturbances are seen in the Greenland magnetometer chain.

[18] The first three panels from the top of Figure 6 show low-energy electron flux $(50-315 \mathrm{keV})$ measured by LANL-01A, LANL-02A, and LANL-97A. During the storm/substorm activity presented in Figure 5 these satellites are located at 2324 UT, 1930 UT, and 1706 UT, respectively. The associated injection front of energetic particles from the second substorm intensification first hits LANL-01A at
1950 UT and somewhat later LANL-02A and is subsequently observed by LANL-97A as the injection front has propagated further to this longitude. Thus based on the above observations, the onset is most likely located somewhere above northern Scandinavia in the premidnight sector. The successive injections from the later intensifications are harder to identify due to the already high energetic particle environment due to the first injection.

[19] In the following we would like to concentrate on the two major intensifications around 2000 UT (2 and 3 in Figure 5), as they are both associated with major poleward expansions, reach very extreme values, display both extreme and fast quenching of current flow, and originate from similar regions in the geomagnetic tail, mainly mapping toward the latitude of MUO. Note, however, that a much smaller substorm intensification at around 2023 UT displays most of the features as well, including magnetic features at Cluster and in the SYM-H index, indicating a similar but much weaker effect as discussed for the main events. The substorm intensifications at 1948 UT and 2003 UT appear to be closely associated with compressions of the magnetosphere. The GOES-12 satellite is located on the dayside magnetosheath at the time of the events (see Figure 1), and it records two distinct periods of intensified pileup of negative magnetic flux in the $B_{z}$ component at 1948 UT and 2003 UT (shaded region in panel 5 of Figure 6). These magnetic flux increases occur almost simultaneously as the two major substorm-like magnetic bays, seen by the ground-based magnetometers in Fenno-Scandinavia. Such flux pileup could either be explained by sudden southward turnings of the IMF $B_{z}$, or by pressure pulses compressing both the magnetosheath and magnetopause, thereby triggering the two observed substorm-like disturbances almost immediately. In order to clarify the occurrence of magnetospheric compressions at these times we have furthermore inspected data from the Cluster satellites, which at this time were located in the western tailward flank of the magnetotail (see Figure 2). The Cluster CIS and FGM data (panel 6 and 8 from the top in Figure 6) show clear evidence of two inward and consecutively outward motions of the magnetopause at 1949 and 2004 UT. The delay time between the Cluster and GOES-12 corresponds to the propagation time of the associated solar wind disturbances to the location of Cluster. The proton bulk speed observed with the CIS instrument is mainly in the negative $\mathrm{X}_{\mathrm{GSM}}$ direction with a smaller component in the positive $Y_{G S M}$ direction as expected for the streaming solar wind plasma in the magnetosheath at this location.

[20] We note that the magnetic field data of Cluster and GOES-12 is almost identical, and furthermore in very good agreement with the simultaneous observations of two instantaneous reentries into the magnetosphere of another geosynchronous spacecraft located on the dayside, LANL 1991-080, at the time of the two relaxations of the magnetosphere, 2002 and 2013 UT (see panel 4 from the top in Figure 6). The simultaneous observations of Cluster, GOES12 and LANL 1991-080 suggest that the entire global magnetopause was in motion during these events. In the following we would like to find candidate mechanisms for these global events.

[21] From the ACE magnetic field data in the two lower panels of Figure 6 we cannot find any clearly associated 


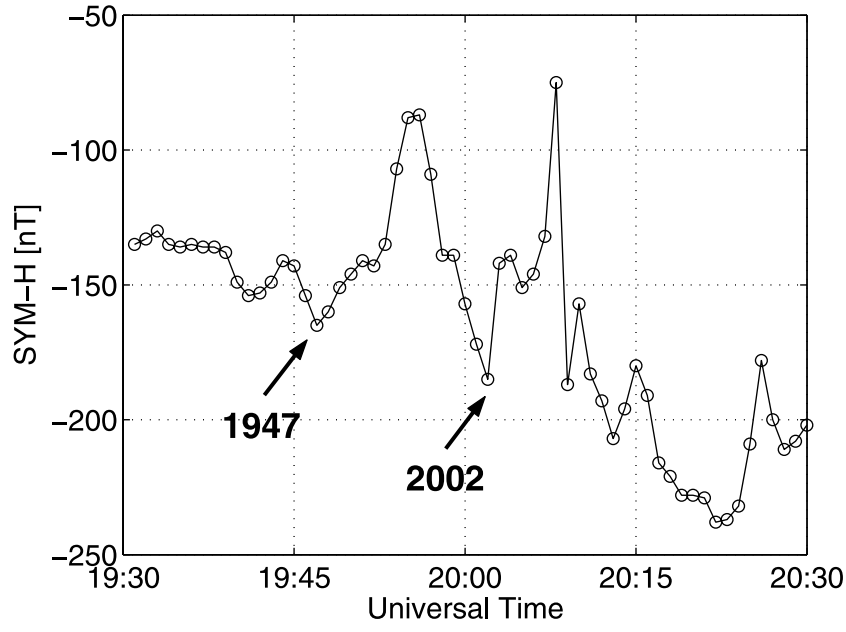

Figure 7. The SYM-H index from WDC, Kyoto, during the a time interval 1930 to 2030 UT where two clear negative deviations at 1947 UT and 2002 UT can be identified and associated to pressure pulses in the solar wind.

turnings of the magnetic field that could be responsible for the observed inward and outward motions of the magnetopause. A small northward turning is seen in the $\mathrm{B}_{z}$ component together with a reduction of the $\mathrm{B}_{y}$ component shortly before the second crossing $(\sim 1957$ UT) and associated substorm-like intensification, but the time difference ( $\sim 6 \mathrm{~min}$ ) is far less than the propagation time from the L1 point to the magnetopause $(\sim 17 \mathrm{~min}$ assuming an average solar wind speed of $1500 \mathrm{~km} / \mathrm{s}$ and the solar wind front to be orthogonal to the Sun-Earth line). Therefore this small event cannot be the responsible trigger. Owing to the sparse (33-min resolution) and rather poor reliability of the ACE/SWEPAM data it is unfortunately not possible to present observational proof of possible pressure pulses that could be responsible for the compressions. However, we have inspected other ground-based magnetic data, which is often used as a proxy for changes in the solar wind dynamic pressure. The SYM-H (Dst) index responds closely to such changes according to the empirical relation $\Delta(\mathrm{Dst}) \sim$ $7.24 \sqrt{\mathrm{P}_{\mathrm{dyn}}}$ (units of $\mathrm{nT}$ and $\mathrm{nP}$ ) [O'Brien and McPherron, 2000]. A closer look at the SYM-H index from panel four in Figure 3 reveals that several such pulses occur during the entire storm event. However, of interest in this study are the two (or three) pulses occurring near 2000 UT on 30 October. We show the SYM-H index around this time with higher resolution in Figure 7. Two clear pulses begin at about 1947 UT and 2002 UT in very good agreement with the observations made by the other instruments above. A third pulse can be identified somewhat later at 2022 UT which might be associated to the smaller substorm intensification at 2023 UT. This strongly supports our initial hypothesis that the compressions and relaxations of the magnetosphere can be attributed to enhanced dynamic pressure in the solar wind. The SYM-H data can even be used to estimate the magnitude of these solar wind pressure increases to about $17.2 \mathrm{nP}$ (for a $\Delta \mathrm{SYM}-\mathrm{H}$ of $30 \mathrm{nT}$ ) for the first pulse and $47.7 \mathrm{nP}$ (for a $\Delta \mathrm{SYM}-\mathrm{H}$ of $50 \mathrm{nT}$ ) for the second pulse according to the relation above. The observed compression and relaxation times of the magnetopause at the different locations are summarized in Table 1.

[22] The MUO magnetogram is shown in panel 7 of Figure 6. It can be seen that while an initial deviation of the magnetogram starts already some minutes before the observed inward motion of the magnetopause at Cluster, the fast and intense substorm-like intensification does not commence until a few minutes after the magnetopause compression. The overall regional response of the entire enhanced westward electrojet system to the compressions of the magnetosphere is better illustrated in Figure 8. Figure 8 shows the westward electrojet, in the left panel, derived from the one-dimensional upward field continuation of the X-component of a north-south IMAGE magnetometer chain to the ionosphere [Vanhamäki et al., 2003] and the total westward (blue) and eastward (red) current in the right panel. This method shows the evolution of the latitudinal extent of the westward electrojet. The times for the associated compressions (relaxations) of the magnetosphere detected by Cluster are marked by solid black (grey) lines in the figure. The compression-related onsets of two substorm intensifications at the latitude of MUO are clearly seen as well as the propagation and intensification of the first onset to latitudes further south. This particular presentation of magnetic data from a latitudinal magnetometer chain in Figure 8 also illustrates quite clearly that both substorm-like intensifications do not display the typical recovery phase features associated with fully developed substorm intensifications. In contrary, both episodes of large and violently enhanced electrojet intensities (total current exceeds 7.4 MA, see right panel of Figure 8) end as abruptly as they are initiated, indicating a possible substorm-quenching, typically due to magnetopause relaxation or decompression, as earlier reported by Karlsson et al. [2000].

[23] The magnetic bays occurred after the IMF $B_{z}$ had been negative for almost 2 hours and the tail magnetic field appeared considerably stretched. Thus there was more than sufficient stored energy available in the tail for a substorm to happen any time, but somehow (for reasons not fully understood during this extreme case of solar wind forcing) the magnetosphere maintained enough stability with regards

Table 1. Observed Times of Compression (C) and Relaxation (R) of the Magnetopause at Different Locations ${ }^{\mathrm{a}}$

\begin{tabular}{lccccc}
\hline \multicolumn{1}{c}{ Observer } & Location & First C, UT & First R, UT & Second C, UT & Second R, UT \\
\hline SYM-H & Ground & 1947 & - & 2002 & - \\
GOES-12 & Dayside & 1948 & - & 2003 & - \\
Cluster & Flank & 1949 & - & 2004 & - \\
LANL 1991-080 & Dayside & - & 2002 & - & 2013 \\
Magnetometer, MUO & Ground & 1948 & - & 2003 & - \\
\hline
\end{tabular}

${ }^{\text {a }}$ The corresponding substorm intensification times are given as a reference in the bottom row. 

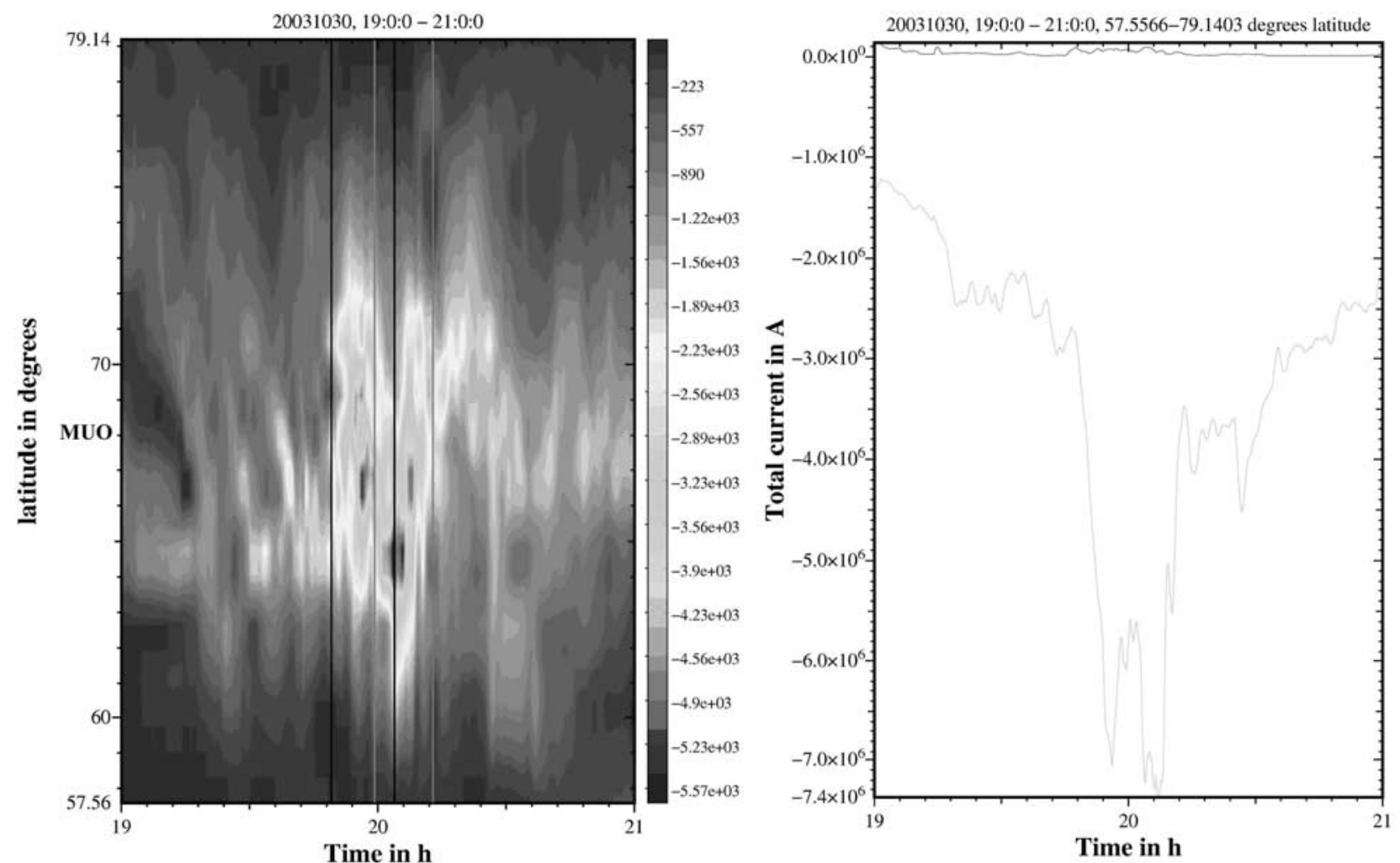

Figure 8. (left) Detection of the westward electrojet through an one-dimensional upward field continuation of the X-component from a north-south IMAGE (NUR-NAL) to the ionosphere. The time of the compressions and relaxations of the magnetosphere as seen by Cluster is shown by solid black and grey lines, respectively. (right) The total integrated eastward (red) and westward (blue) currents. See color version of this figure at back of this issue.

to standard substorm onset mechanisms. However, two rapid and, considering the Cluster data, effective compressions and consecutive decompressions of the entire magnetosphere managed to enforce two extremely strong substorm-like energy releases from the tail, almost like squeezing a gigantic sponge, which would also explain why both electrojet intensifications die out almost as fast as they started, as soon as the magnetospheric compression relaxes. A third dynamic pressure pulse might have been responsible for a third less intense energy release occurring at lower latitudes, maybe due to the highly dipolarized configuration of the magnetosphere after the first two events.

[24] In the following, we will inspect further ionospheric data, as to better illustrate the detailed nature of these extreme electrojet enhancements.

\subsubsection{Energy Dissipation in the Ionosphere}

[25] The EISCAT radar provides unique means to study the coupling of solar wind variability or magnetospheric dynamics with the ionosphere, as it allows the simultaneous observation of a number of ionospheric parameters, like, e.g., the ionospheric vector electric field and the ionospheric conductivities. We have inspected some EISCAT data from an ionospheric region slightly north of the latitude of MUO, a latitude region which we have shown is highly responsive to both of the major substorm-like intensifications of the auroral electrojet during the main phase of an ICME. The purpose of this inspection is to identify unusual (or alter- natively normal but extreme) behavior of the ionospheric plasma, giving rise to such strong magnetic disturbances.

[26] The top panel in Figure 9 shows the electron density in the ionospheric $E$ and lower $F$ region, as seen by the EISCAT UHF radar in Tromsø. It is evident from this data that the precipitation during the first two main substorm intensifications, i.e., right before and shortly after 2000 UT is very energetic (several tens of $\mathrm{keV}$ ) since the ionization reaches very low altitudes. The first substorm intensification appears to be located close to the latitude of EISCAT, while the second (and the successive ones at 2023 UT and after 2100 UT) occur offset from the EISCAT beam. From inspection of Figure 8 we can conclude that they must be located southward of EISCAT.

[27] These localized enhancements of ionization associated with the strong precipitation drastically change the properties of the ionospheric conductivity. In Figure 9 we show the Pedersen and Hall conductivity $\left(\sigma_{P}, \sigma_{H}\right.$, panels 2 and 4$)$ and conductances $\left(\Sigma_{P}=\int \sigma_{P} d z, \Sigma_{H}=\int \sigma_{H} d z\right.$, panels 3 and 5). The conductivities were calculated from the observed electron density, the electron temperature profiles (assuming $T_{e}=T_{n}$ ) employing the MSISE90 [Hedin, 1991] neutral atmosphere model, and ion-neutral and electronneutral collision frequencies according to Kelley [1989].

[28] The electric fields (panel 6 from the top in Figure 9) have been evaluated with identical results using independently two different methods from RAL and Grenoble, based on the line-of-sight plasma flow components mea- 


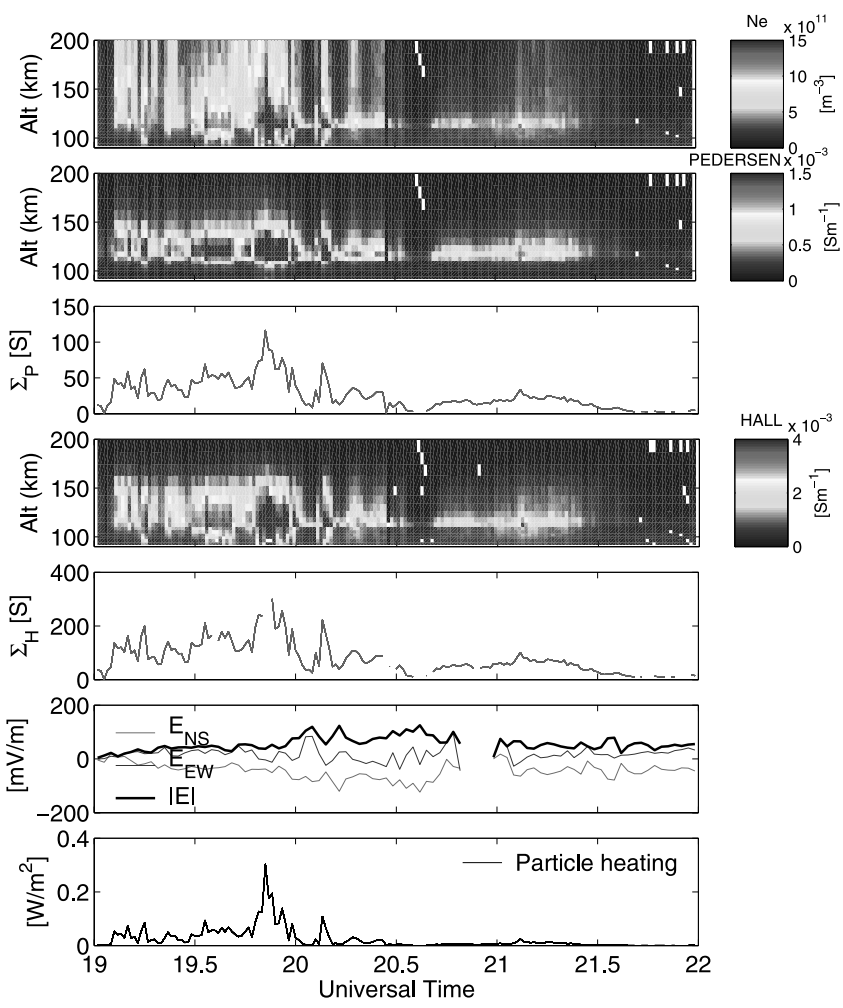

Figure 9. One-minute resolution of EISCAT data (Tromsø-UHF) displaying from top to bottom the electron density, Pedersen conductivity and conductance, Hall conductivity and conductance, the horizontal and total electric field, and the energy dissipation due to precipitating electrons. See color version of this figure at back of this issue.

sured at EISCAT Tromsø and at the two other receiving stations in Kiruna and Sodankylä from the same ionospheric volume.

[29] From the original data we can already conclude that the first electrojet intensification before 2000 UT is caused by an extreme enhancement of ionospheric conductivity, due to the very enhanced and energetic electron precipitation. Hall conductances as large as seen here, over $300 \mathrm{~S}$, and over $100 \mathrm{~S}$ for the Pedersen conductance are among the highest conductances reported by EISCAT. During this first event the electric field remains relatively moderate, of the order of $50 \mathrm{mV} / \mathrm{m}$, but considering the usual and well known anticorrelation [Baumjohann and Opgenoorth, 1984] of electric fields and ionospheric conductivity in active aurora due to polarization electric fields, fields of several tens of $\mathrm{mV} / \mathrm{m}$ in westward and southward direction must be considered as high within such extreme auroral conductivity. Not surprisingly, the associated electrojet intensification produces one of the largest magnetic disturbances observed in northern Scandinavia.

[30] During the second electrojet intensification shortly after 2000 UT the observed conductivities are considerably lower than in the previous event, but the electric field is now almost $100 \mathrm{mV} / \mathrm{m}$ in the southward direction. As already concluded above this may be a consequence of the main auroral electrojet event being located to the south of the radar, such that EISCAT only sounds the northern edge of the precipitation, where the field is known to be strong and directed toward the precipitation region [Opgenoorth et al., 1983; Baumjohann and Opgenoorth, 1984]. However, in this case the observed electric field of $100 \mathrm{mV} / \mathrm{m}$ in combination with a Hall conductivity of close to $200 \mathrm{~S}$ must be considered as an extreme situation, again leading to very high currents ( $>7.4 \mathrm{MA}$ according to Figure 8 ).

[31] A closer inspection of the second event also reveals a fast equatorward motion of the precipitation region after onset. EISCAT sees initially a strong conductivity enhancement and a reduction of the electric field at 2005 UT, followed by a rapid decrease of conductivity and increase of the mainly southward electric field, which implies a rapid motion of the poleward precipitation boundary toward south, over the EISCAT beam. This is in agreement with our other conclusions about the electrojet development in Figure 8, where we concluded that both events basically originated close to MUO. Measurements of the ionization of the $E$ region allows us to further estimate the rate of the ionospheric energy dissipation due to particle heating. The rate of height-integrated energy deposition from particle precipitation is shown in the bottom panel of Figure 9. Also in this presentation it becomes clear that the substorm intensification at 1948 UT is located right at the latitude of Tromsø (see Figures 5 and 1, noting that the SOR magnetogram is closest to the latitude of Tromsø) and EISCAT observes strong precipitation and thus strong particle heating (about $300 \mathrm{~mW} / \mathrm{m}^{2}$ ) associated with this event.

\section{Discussion}

[32] In the following, we would like to discuss the most plausible cause of the observed extreme substorm-like disturbances, taking into account all our observations in the solar wind-magnetosphere system. Furthermore, the predictability of such extreme events within the framework of space weather initiatives will be reviewed.

[33] In the current study we have presented an example of what we believe to be externally triggered substorms or substorm-like activity driven by moderate pressure pulses in the solar wind. They occur several hours after an initial interplanetary shock compression of the magnetosphere in the middle of the $B_{z}$ negative phase of ICME encounter. Our conclusions are based on the simultaneous observation of substorm intensifications, associated with Cluster magnetopause crossings and GOES-12 observations of magnetosheath flux pileup. Finally, we have used the SYM-H index as a proxy for identifying pressure pulses in the solar wind responsible for the changing magnetospheric dynamics since direct observations could not be made due to the saturation of the ACE/SWEPAM instrument. However, using restored data from instruments on board ACE and a model of the magnetopause location under extreme solar wind conditions developed by Shue et al. [1998] allows us at least to draw qualitative and quantitative conclusions whether the solar wind conditions were sufficient for the observed Cluster magnetopause crossings to be caused by moderate pressure changes within the main body of the ICME.

[34] We have used restored ACE data with a time resolution of approximately $33 \mathrm{~min}$ to estimate the last 


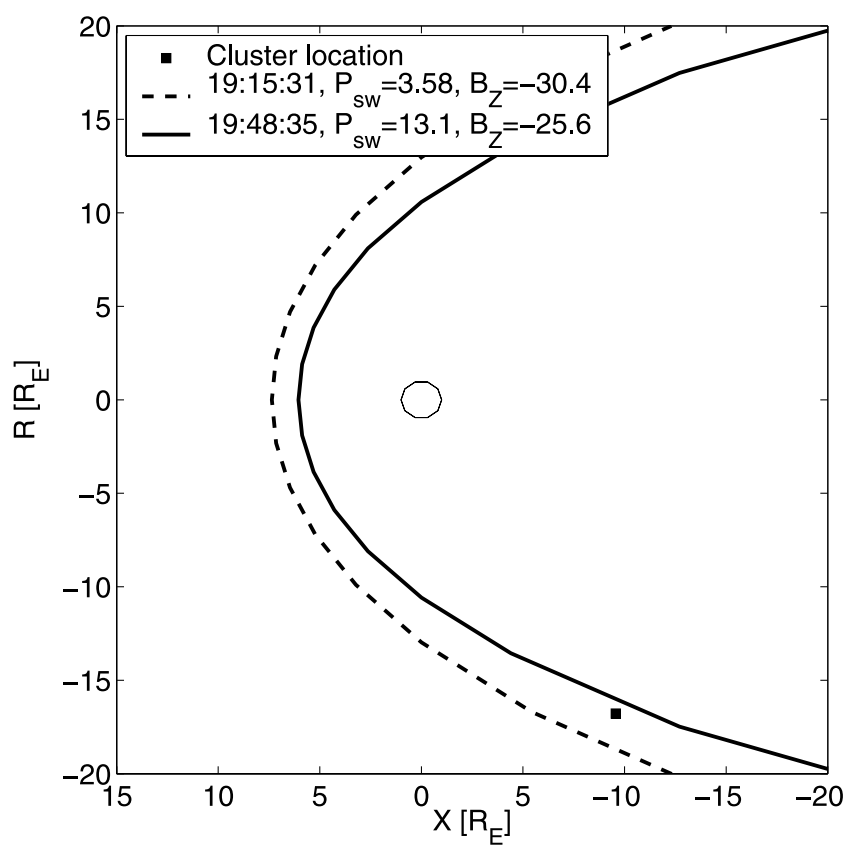

Figure 10. Location of the magnetopause and Cluster before and after the major disturbances at 1948 UT and 2003 UT as predicted by the Shue et al. [1998] magnetopause model and the solar wind characteristics measured by ACE assuming a time delay of about $17 \mathrm{~min}$ from L1 point to the Earth.

solar wind pressure value before the first magnetopause crossing (1915:31 UT) and the subsequent record approximately half an hour later was taken as the example of an increased solar wind pressure during the first event, taking into account a time shift corresponding to the travel time of the solar wind to the magnetopause (approximately $17 \mathrm{~min}$ ).

[35] The resulting locations of the magnetopause before and after the events discussed are shown in Figure 10 together with the location of the Cluster spacecraft. According to the used model and the two measured solar wind quantities, the changes were sufficient to compress the magnetopause to within the position of Cluster, at least for the first event. Similarity considerations between the two events, and all the other evidence presented above, should already allow us to attribute both events to triggering by solar wind pressure variations.

[36] However, we have also inspected two other useful methods to evaluate the spatial dynamics of the magnetopause motion, both utilizing the 4-point Cluster measurements. First, the boundary normals have been evaluated from minimum variance analysis of magnetic field vector data acquired by each of the four spacecrafts as they traverse the magnetopause. For the four inbound, respectively outbound crossings the normal was found to be mainly in the $\mathrm{Y}_{\mathrm{GSE}}$ direction with little or no variation in the normal direction estimate from the four satellites. This suggest that the magnetopause then was acting like a planar structure, at least at the scale of the spacecraft separation (about $100 \mathrm{~km}$ ). In addition, a 4-point technique of the relative positions and timings of the satellites have been used to construct both the boundary normal and speed. The resulting estimates of the normal are found to be consistent with the above result, confirming the planar magnetopause structure. The normal velocity of the magnetopause was of the order of $100 \mathrm{~km} / \mathrm{s}$ for the two inbound crossings (which we interpret as compressions). The derived normal directions and the inferred sign of the normal velocity from the timing and the minimum variance technique are consistent with the other observations. We therefore suggest that the magnetopause undergoes an inward and consecutively outward motion which can be attributed to pressure variations in the solar wind.

[37] We further note that there is an apparent time delay of the order of a few minutes between the first deviations of the ground-based magnetograms with respect to the arrival of the magnetopause at Cluster. We believe that this can be accounted for by the time it takes to compress the magnetopause from its initial position to within the location of Cluster. Using the derived magnetopause velocity this motion would take about $60 \mathrm{~s}$ for each $\mathrm{R}_{E}$ distance covered thus resulting in a timing uncertainty of several minutes according to the locations in Figure 10. One should note that the magnetosheath flux pileup by GOES-12 shows exactly the same temporal pattern as Cluster exits and reenters from and into the magnetosphere, with a corresponding time delay for propagation from the subsolar magnetopause to $-10 \mathrm{R}_{E}$. The observed variations in the magnetosheath precede the magnetospheric and ionospheric disturbances (see Figure 6).

[38] Hsu and McPherron [2003] found that 3\% out of the total $7 \%$ of the events triggered by dynamic pressure pulses were not related to any changes in $B_{z}$ or $B_{y}$. The events were found to be associated with pressure pulse triggering if the solar wind plasma pressure increased as a step function by a magnitude larger than $7 \mathrm{nP}$. One can note that the pressure in this case increased by at least $10 \mathrm{nP}$, according to low resolution ACE data before and after the substorm onsets which is larger than the criteria used by Hsu and McPherron [2003] (see Figure 10). In addition, the estimated values of the two pulses from the SYM-H index, $17.2 \mathrm{nP}$ and $47.7 \mathrm{nP}$, also fall within the limit of this criterion.

[39] A theory on how the interaction of solar wind pressure pulses with the Earth magnetosphere can trigger substorm onsets has been proposed by Liou et al. [2003]. The high solar wind ram pressure compresses the dayside magnetosphere and increases the magnetopause current. As the high-pressure solar wind moves tailward, also the lobe magnetic field becomes more compressed thus enhancing the cross-tail currents and causing the plasma sheet to thin. If this thinning becomes strong enough to let the ion motion become nonadiabatic, magnetic reconnection can be initiated and a substorm will be triggered if the rate of reconnection grows explosively. This mechanism ought to be even more effective, if the magnetosphere is already preconditioned, that is extremely stretched, due to an ongoing reconnection cycle during a period of extended negative IMF $B_{z}$. In this case we have observed extreme substorm-like intensifications after several hours of strong negative $B_{z}$.

[40] We conclude that the two extreme substorm-like events and in addition a third smaller event presented here are closely related to medium-scale pressure pulses in the solar wind several hours after the arrival of the initial ICME responsible for the geomagnetic storm. The dynamic pres- 
sure variations in the solar wind occurring within a short time period of each other generated complicated electrojet variations in which the effect of the previous still remained when a successive pulse hit the magnetosphere resulting in a reintensification of the electrojet system. It is astonishing to see that even though the IMF has been strongly southward directed for hours prior to this event, there is no train of consecutive substorms, as would most likely be the case for a more moderate period of southward IMF in a normal unshocked solar wind. While we cannot explain the observed stability of the magnetosphere vis-á-vis standard substorm excitation mechanisms during the storm main phase, the presented study can associate two extreme substorm-like electrojet and precipitation intensifications with pressure pulse triggers, causing magnetospheric compressions of an overstretched magnetosphere.

[41] Throughout this paper we prefer to call the precipitation and electrojet enhancements events "substorm-like," as they apparently lack other typical features as, e.g., a substorm growth phase and a recovery phase. In fact, both events look like isolated expansion phases, pure and extreme magnetospheric energy releases, with all the right ingredients in the magnetosphere and ionosphere but with no recovery. The observed relaxations of the magnetosphere appear to quench both events basically immediately. It appears almost like the solar wind squeezes the magnetosphere like a gigantic sponge, activating only one part of the substorm instability chain in the near-Earth tail, releasing enormous amounts of stored energy in very short time, and abruptly stopping the process by consecutive relaxation. The overcritical but stable state of the magnetosphere prior to these solar wind triggers may also explain why we see events to occur basically immediately, within a timing uncertainty of only a few minutes, which is of the order of the information travel time in the magnetosphere.

\section{Conclusions}

[42] We have investigated the similarities and differences between two large geomagnetic storms on 29 and 30 October 2003 with respect to the solar eruption, the solar wind driver, and the associated terrestrial response. On the basis of comparisons between these two events the compressed negative $B_{z}$ in the leading field of the magnetic cloud seem to have the most prominent geoeffectivness regardless of other cloud characteristics such as shock strength, sheath fields, duration of the compressed region, and the velocity of the cloud.

[43] We further report on the observations of some of the strongest magnetospheric and ionospheric disturbances ever seen. They occurred in close association but were not directly linked to some of the largest solar flares and coronal mass ejections ever observed. The energy dissipation in the ionosphere during these events was extremely strong. The particle heating rate was several hundreds of $\mathrm{mW} / \mathrm{m}^{2}$ and this is the largest recorded value found in any literature so far. Furthermore, the extreme changes in the magnetic field on ground level, as caused by the abnormally large substorm-like electrojet enhancement over northern Scandinavia have driven geomagnetically induced currents responsible for overheating of an electric network transformer in Malmö causing a power loss to 50,000 inhabitants.

[44] The prediction of such or similar events is a major, but as our study shows, very problematic goal of space weather researchers. As we have shown above, an extended period of strong solar wind pressure and southward directed IMF can apparently only drive the magnetosphere subcritically unstable to substorm-onset mechanisms. In this state, which can be maintained for extended periods of time, small-scale variations of the solar wind pressure, or other solar wind drivers leading to magnetospheric compression, can release extreme amounts of stored energy with virtually no time delay after the arrival of the disturbance at the subsolar magnetopause.

[45] Unfortunately, in this particular case the exact dynamic behavior of the solar wind before, during, and after the main event could not be studied in sufficient detail, because of the saturation of the principal "watchdog" satellite at the L1 point. The observations presented in this paper imply that similar studies need to be carried out for less extreme events. They also demonstrate the need for new saturation-safe equipment at key heliospheric locations to study the solar wind-magnetosphere interaction during the most disturbed conditions, which have the most important implications for human activities.

[46] Acknowledgments. We thank the international consortium of institutes that maintains the IMAGE magnetometer array. The PI institute for IMAGE is the Finish Meterorological Institute. The Greenland magnetometer data was provided by the Danish Meteorological Institute (DMI). The satellite data for the LANL geostationary satellites was provided by the Los Alamos National Laboratory (LANL). EISCAT is an International Association supported by Finland (SA), France (CNRS), the Federal Republic of Germany (MPG), Japan (NIPR), Norway (NFR), Sweden (VR), and the United Kingdom (PPARC). Special thanks to V. Howells and K. Freeman for providing help with analysing the EISCAT data. We acknowledge the use of geomagnetic data from the World Data Center for Geomagnetism in Kyoto. The data provider for H0-ACE data are CDAWeb and we thank the PI N. Ness of Bartol Research Institute. We also thank T. Zurbuchen from the University of Michigan, Department of Atmospheric, Oceanic, and Space Sciences for providing the revised ACE/SWEPAM data. We also thank the PIs (H. Réme for CIS and A. Balogh for FGM) and data providers for Cluster. Thanks also to R. Behlke for providing Figure 2. We furthermore are very grateful to one referee for the very kind provision of the SYM-H index data which has added a crucial element to our discussion.

[47] Arthur Richmond thanks Robert L. McPherron and another reviewer for their assistance in evaluating this paper.

\section{References}

Baker, D. N., T. I. Pulkkinen, V. Angelopoulos, W. Baumjohann, and R. L. McPherron (1996), Neutral line model of substorms: Past results and present view, J. Geophys. Res., 101, 12,975.

Balogh, A., et al. (2001), The Cluster magnetic field investigation: Overview of inflight performance and initial results, Ann. Geophys., 19, 1207.

Baumjohann, W., and H. J. Opgenoorth (1984), Electric fields and currents associated with active aurora, in Magnetospheric Substorms, Geophys. Monogr. Ser., vol. 64, pp. $77-85$, edited by T.A. Potemra, AGU, Washington, D. C.

Baumjohann, W., Y. Kamide, and R. Nakamura (1996), Substorms, storms, and the near-Earth tail, J. Geomagn. Geoelectr., 48, 177.

Burch, J. L. (1972), Preconditions for the triggering of polar magnetic substorms by storm sudden commencements, J. Geophys. Res., 77, 6529. Burlaga, L. F., E. Sittler, F. Mariani, and R. Schwenn (1981), Magnetic loop behind an interplanetary shock, Voyager, Helios, and IMP8 observations, J. Geophys. Res., 86, 6673.

Burlaga, L. F., K. W. Behannon, and L. W. Klein (1987), Compound streams, magnetic clouds, and major geomagnetic storms, J. Geophys. Res., 92, 5725.

Escoubet, C. P., M. Fehringer, and M. Goldstein (2001), The Cluster mission, Ann. Geophys., 19, 1197. 
Fairfield, D. H., and L. J. Cahill (1966), Transition region magnetic field and polar magnetic disturbances, J. Geophys. Res., 71, 155.

Folkestad, K., T. Hagfors, and S. Westerlund (1983), EISCAT: An updated description of technical characteristics and operational capabilities, Radio Sci., 18,876

Friis-Christensen, E., Y. Kamide, A. D. Richmond, and S. Matsushita (1985), Interplanetary magnetic field control of high-latitude electric fields and current determined from Greenland magnetometer data, J. Geophys. Res., 90, 1325.

Gonzalez, W. D., B. T. Tsurutani, and A. L. Clúa de Gonzalez (1999), Interplanetary origin of geomagnetic storms, Space Sci. Rev., 88, 529.

Hedin, A. E. (1991), Extension of the MSIS Thermospheric Model into the middle and lower atmosphere, J. Geophys. Res., 96, 1159

Hsu, T.-S., and R. L. McPherron (2003), Occurrence frequencies of IMF triggered and nontriggered substorms, J. Geophys. Res., 108(A7), 1307 doi:10.1029/2002JA009442.

Karlsson, S. B. P., H. J. Opgenoorth, P. Eglitis, K. Kauristie, M. Syrjäsuo, T. Pulkkinen, M. Lockwood, R. Nakamura, G. Reeves, and S. Romanov (2000), Solar wind control of magnetospheric energy content: Substorm quenching and multiple onsets, J. Geophys. Res., 105, 5335.

Kelley, M. C. (1989), The Earth's Ionosphere, Elsevier, New York.

Klein, L. W., and L. F. Burlaga (1982), Interplanetary magnetic clouds at $1 \mathrm{AU}$, J. Geophys. Res., 87, 613.

Liou, K., P. T. Newell, C.-I. Meng, C.-C. Wu, and R. P. Lepping (2003), Investigation of external triggering of substorms with Polar ultraviolet imager observations, J. Geophys. Res., 108(A10), 1364, doi:10.1029/ 2003JA009984.

Lui, A. (1996), Current disruption in the Earth's magnetosphere: Observations and models, J. Geophys. Res., 101, 13,067.

Lyons, L. R., G. T. Blanchard, J. C. Samson, R. P. Lepping, T. Yamamoto, and T. Moretto (1997), Coordinated observations demonstrating external substorm triggering, J. Geophys. Res., 102, 27,039.

McPherron, R. L., and T.-S. Hsu (2002), A comparison of substorms occuring during magnetic storms with those occuring during quiet times, J. Geophys. Res., 107(A9), 1259, doi:10.1029/2001JA002008.

O’Brien, T. P., and R. L. McPherron (2000), An empirical phase space analysis of ring current dynamics: Solar wind control of injection and decay, J. Geophys. Res., 105, 7707

Opgenoorth, H. J., R. Pellinen, W. Baumjohann, E. Nielsen, G. Marklund, and L. Eliasson (1983), Three-dimensional current flow and particle precipitation in a westward travelling surge, J. Geophys. Res., 88, 3138

Reeves, G. D., R. D. Belian, T. C. Cayton, R. A. Christensen, M. G. Henderson, and P. S. McLachlan (1996), Los Alamos space weather data products: on line and on time, Proceedings of Third International Conference on Substorms (ICS-3), Versailles, France, edited by E. J. Rolfe, p. 689, Eur. Space Agency Publ. Div., Noordwijk, Netherlands.

Réme, H., et al. (2001), First multispacecraft ion measurements in and near the Earth's magnetosphere with the identical Cluster Ion Spectrometry (CIS) experiment, Ann. Geophys., 19, 1303.

Rostoker, G. A. (1983), Triggering of the expansive phase intensifications of magnetospheric substorms by northward turnings of the interplanetary magnetic field, J. Geophys. Res., 88, 6981.
Schieldge, J. P., and G. L. Siscoe (1970), A correlation of the occurrence of simultaneous sudden magnetospheric compression and geomagnetic bay onsets with selected geophysical indices, J. Atmos. Terr. Phys., 32, 1819.

Shue, J. H., et al. (1998), Magnetopause location under extreme solar wind conditions, J. Geophys. Res., 103, 17,691.

Skoug, R. M., J. T. Gosling, J. T. Steinberg, D. J. McComas, C. W. Smith, N. F. Ness, Q. Hu, and L. F. Burlaga (2004), Extremely high speed solar wind: 29-30 October 2003, J. Geophys. Res., 109, A09102, doi:10.1029/ 2004JA010494

Snyder, C. W., M. Neugebauer, and V. R. Rao (1963), The solar wind velocity and its correlation with solar and geomagnetic activity, J. Geophys. Res., 68, 6361.

Troshichev, O. A., A. L. Kotikov, B. D. Bolotinskaya, and V. G. Andresen (1986), Influence of the IMF azimuthal component on magnetospheric substorm dynamics, J. Geomagn. Geoelectr., 38, 1075.

Tsurutani, B. T., and W. D. Gonzalez (1987), The interplanetary causes of magnetic storms: A review, in Magnetic Storms, Geophys. Monogr. Ser. vol. 98, edited by B. T. Tsurutani et al., pp. 77-89, AGU, Washington, D. C.

Tsyganenko, N. A. (1989), A magnetospheric magnetic field model with a warped tail curent sheet, Planet. Space Sci., 37, 5 .

Vanhamäki, H., O. Amm, and A. Viljanen (2003), 1-dimensional upward continuation of the ground magnetic field disturbance using spherical elementary current systems, Earth Planets Space, 55, 613.

Viljanen, A., and L. Häkkinen (1997), IMAGE magnetometer network, in Satellite-Ground Based Coordination Sourcebook, ESA SP-1198, edited by M. Lockwood, M. N. Wild, and H. J. Opgenoorth, p. 111, Eur. Space Agency, Paris.

Wang, Y., C. L. Shen, S. Wang, and P. Z. Ye (2003), An empirical formula relating the geomagnetic storm's intensity to the interplanetary parameters: $-\overline{v B_{z}}$ and $\Delta t$, Geophys. Res. Lett., 30(20), 2039, doi:10.1029/ 2003GL017901.

Zhang, G., and L. F. Burlaga (1988), Magnetic clouds, geomagnetic disturbances, and cosmic ray decreases, J. Geophys. Res., 93, 2511.

Zhang, J., M. W. Liemohn, J. U. Kozyra, B. J. Lynch, and T. H. Zurbuchen (2004), A statistical study of the geoeffectivness of magnetic clouds during high solar activity years, J. Geophys. Res., 109, A09101, doi:10.1029/2004JA010410.

O. Amm, Finnish Meteorological Institute, Helsinki, Finland

S. Buchert and L. Rosenqvist, Swedish Institute of Space Physics, Lägerhyddsvägen 1, 75121 Uppsala, Sweden. (1r@irfu.se)

C. Lathuillere, Laboratoire de Planétologie de Grenoble, Grenoble, France.

I. McCrea, Rutherford Appleton Laboratory, Chilton, Didcot, UK.

H. Opgenoorth, Research and Scientific Support Department, European Space Agency/European Space Research and Technology Centre, Noordwijk, Netherlands. 


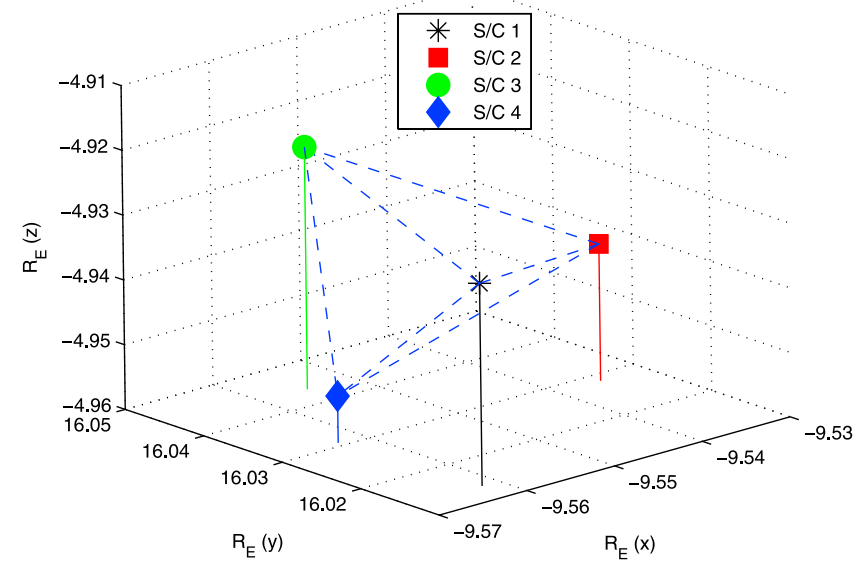

Figure 2. The Cluster s/c relative locations at 2004 UT on 30 October 2003.

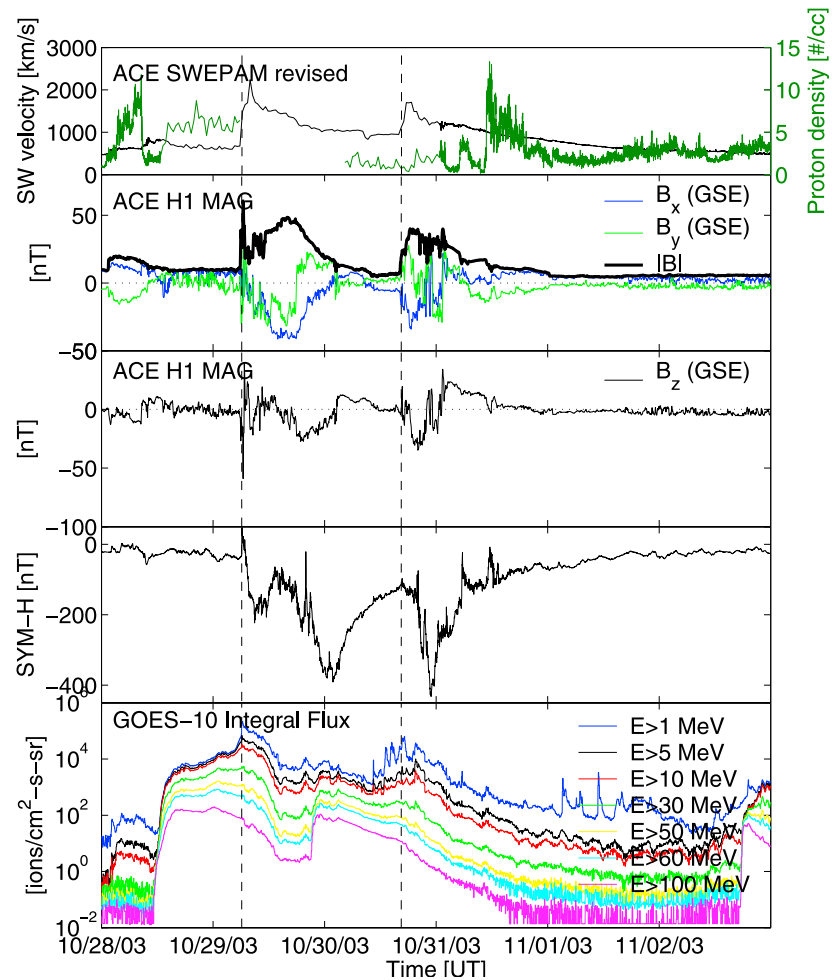

Figure 3. Summary of events of late October to the beginning of November 2003. From top to bottom is the revised ACE SWEPAM solar wind velocity and density (courtesy of T. Zurbuchen), the ACE H1 magnetic field data in GSE coordinates, the SYM-H index, and the integral proton flux from the GOES-10 spacecraft. The vertical dashed lines indicate the arrival of the two geomagnetic clouds at Earth. 


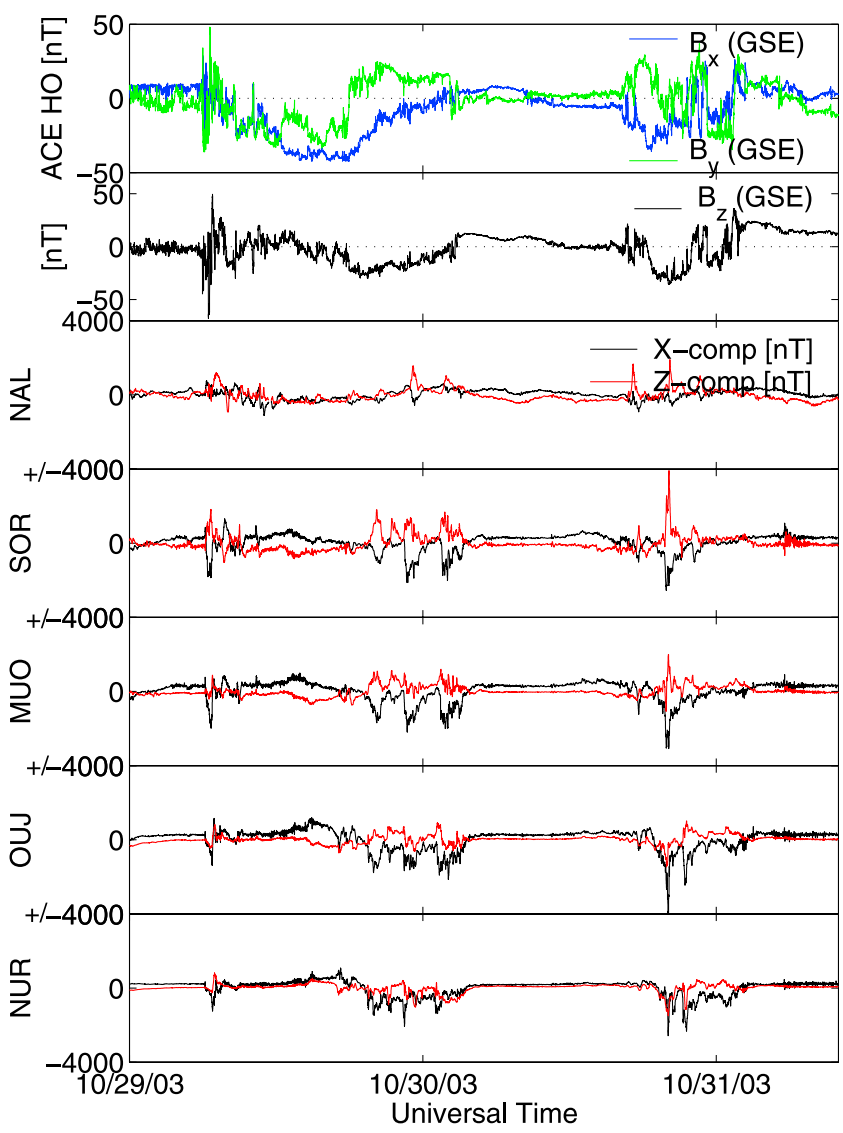

Figure 4. Unshifted solar wind data in GSE-coordinates from ACE H0 (time resolution $16 \mathrm{~s}$ ) and selected $\mathrm{Bx}$ and Bz-component magnetograms from the IMAGE network.

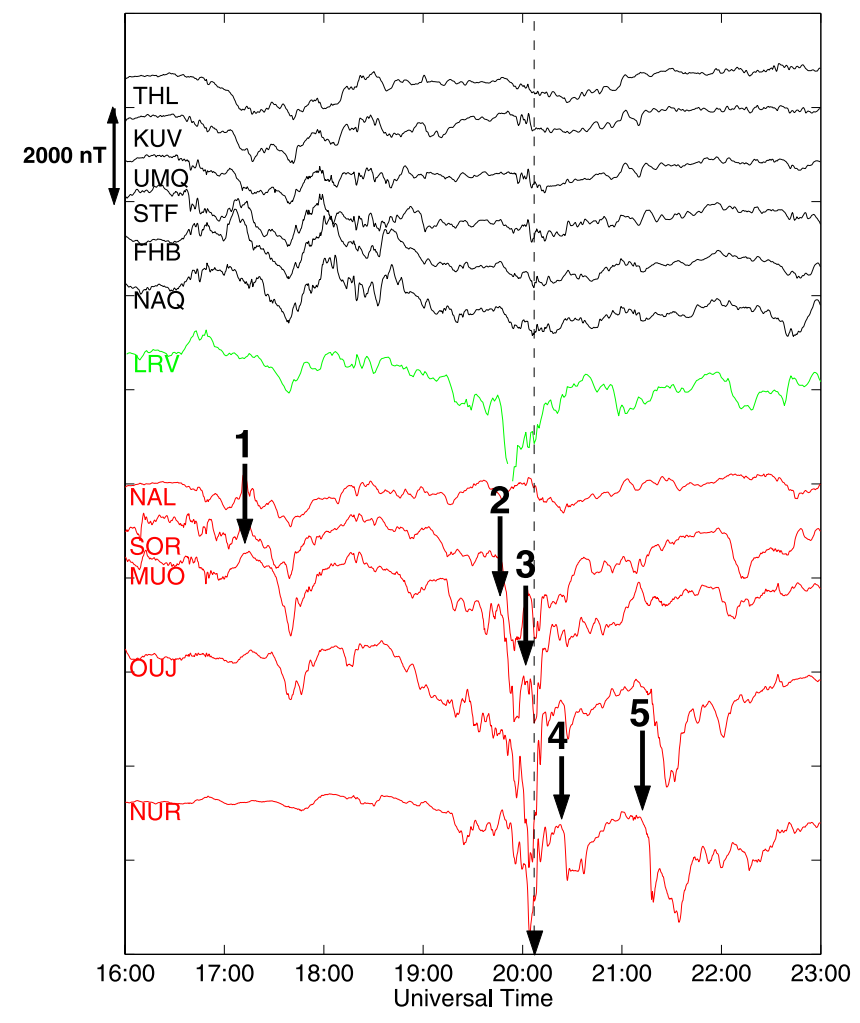

Figure 5. Ground magnetic H-component (Greenland) and X-components (IMAGE, LRV) for different local times. The vertical dashed arrow indicates the time of the power loss in Malmö in southern Scandinavia at 2007 UT. 


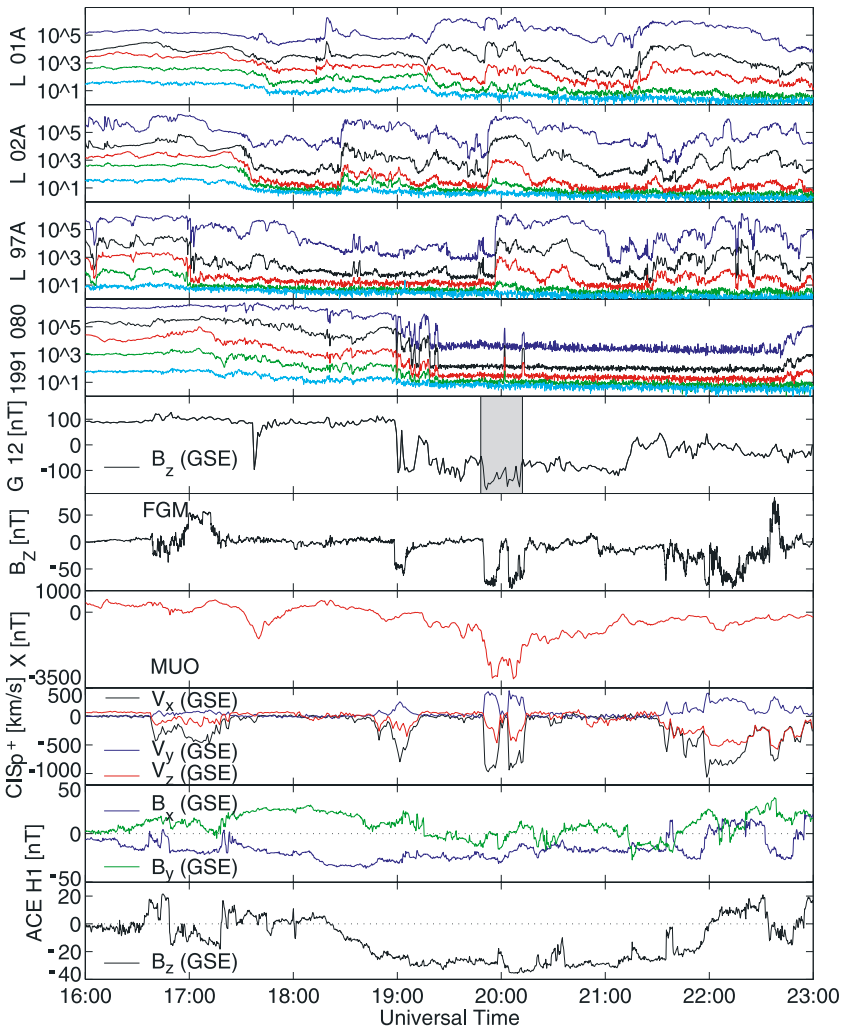

Figure 6. Summary of events on 30 October 2003. From top to bottom are shown low-energy electrons $(50-315 \mathrm{keV})$ from four LANL geosynchronous satellites, magnetic field measurements from GOES-12, magnetic field measurements from Cluster FGM, the X-component from the MUO magnetometer, proton bulk flow velocity from Cluster CIS, and unshifted magnetic field measurements from ACE in the solar wind. 

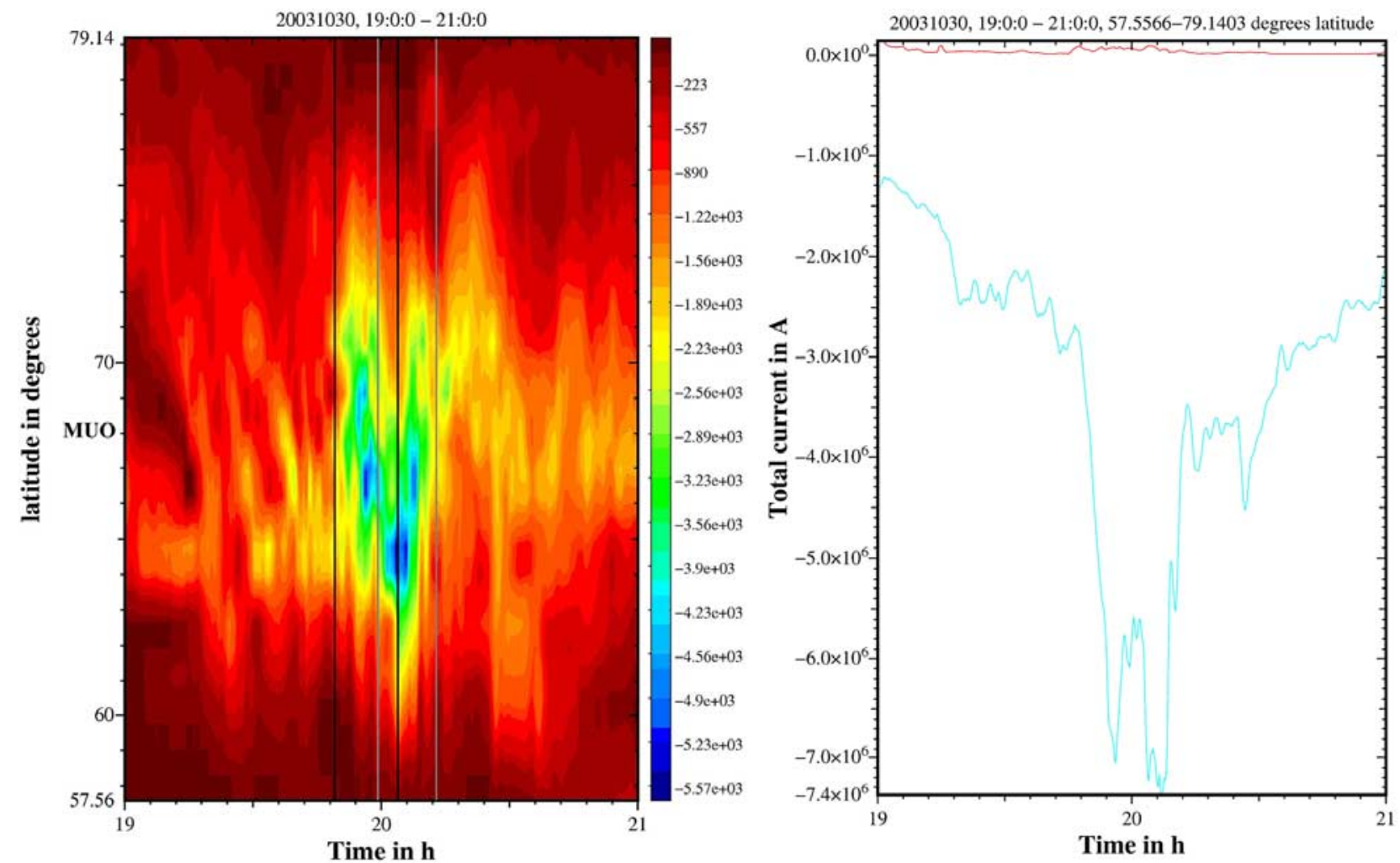

Figure 8. (left) Detection of the westward electrojet through an one-dimensional upward field continuation of the X-component from a north-south IMAGE (NUR-NAL) to the ionosphere. The time of the compressions and relaxations of the magnetosphere as seen by Cluster is shown by solid black and grey lines, respectively. (right) The total integrated eastward (red) and westward (blue) currents. 

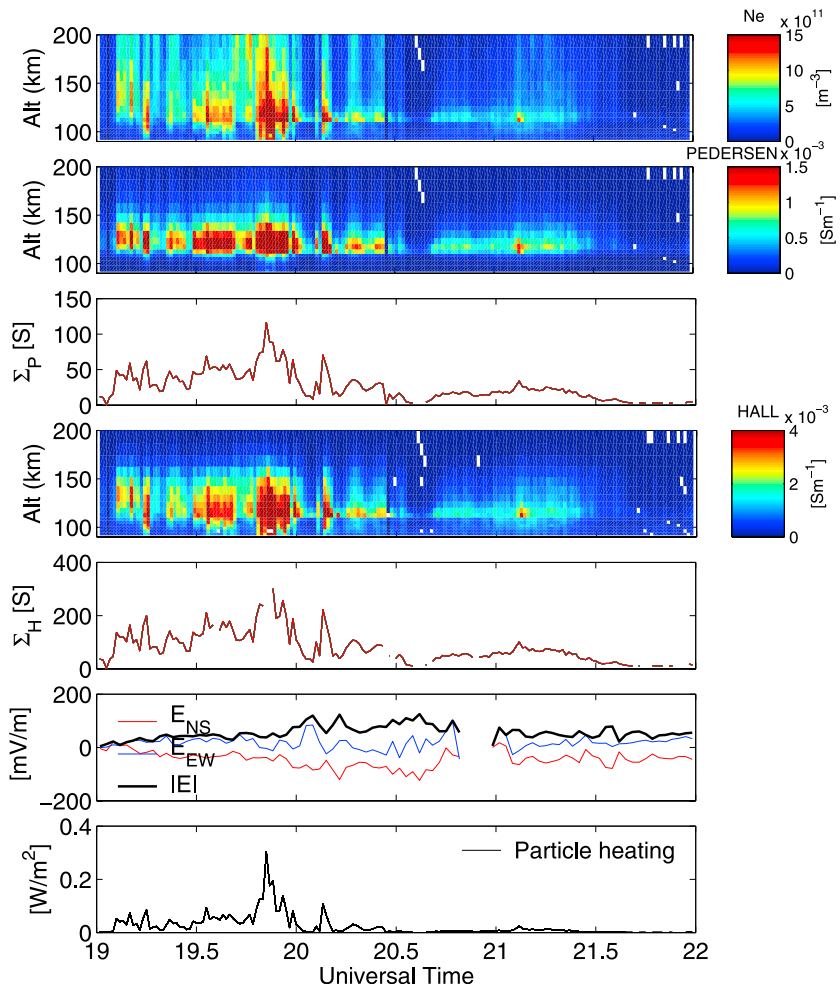

Figure 9. One-minute resolution of EISCAT data (Tromsø-UHF) displaying from top to bottom the electron density, Pedersen conductivity and conductance, Hall conductivity and conductance, the horizontal and total electric field, and the energy dissipation due to precipitating electrons. 